\title{
Absceso profundo de cuello: intubación vigil con fibrobroncoscopia
}

\author{
Carabajal Rodríguez JM. ${ }^{1}$, Rojas S. ${ }^{1}$, Avila R. ${ }^{1}$, Acosta Larrosa M. ${ }^{1}$, Díaz NB. ${ }^{1}$ \\ 1 Hospital Regional Ramón Carrillo, Santiago del Estero, Argentina.
}

Introducción: Es un proceso inflamatorio - infeccioso de las fascias cervicales. Causas: invasión de bacterias de flora bucal, generalmente polimicrobiana con predominio de anaerobios. Clínica: disfagia, odinofagia, disnea, síndrome febril, dolor cervical, trismus, adenopatías. Tratamiento: antibióticos de amplio espectro - drenaje quirúrgico. Complicaciones: mediastinitis, neumonía, derrame pleural, tromboembolismo pulmonar, insuficiencia respiratoria aguda, lesión vascular, sepsis y falla orgánica múltiple.

Descripción del caso clínico: Paciente sexo masculino de 32 años ingresa a quirófano con diagnóstico de absceso dental - cervical con el fin de realizar cervicotomía universal derecha. Antecedentes patológicos: consumo de tabaco y alcohol, obesidad (IMC $40 \mathrm{~kg} / \mathrm{m} 2$ ), ASA III. Estable hemodinamicamente, saturación 97\% (cánula nasal con 3 lts/min de oxígeno). Examen complementarios: ECG; Radiografía de Tórax; TAC de cuello; laboratorio (leucocitosis con neutrofilia). Valoración de vía aérea: ventilación dificultosa (masculino, IMC $40 \mathrm{~kg} / \mathrm{m} 2$, Mallampati 4); intubación dificultosa (incapacidad de protrusión mandibular - trismus - apertura bucal $<2 \mathrm{~cm}$ - distancia tiromentoniana $<6 \mathrm{~cm}$ - circunferencia de cuello $>40 \mathrm{~cm}$ - movilidad cervical limitada - Mallampati 4 - macroglosia). Monitorización ECG - presión arterial no invasiva - oximetría de pulso - capnografía. Se realiza intubación vigil mediante fibrobroncoscopia con tubo endotraqueal $\mathrm{N}^{\circ} 7$ (premedicación fentanilo $150 \mathrm{mcg}$ ev; lidocaína $2 \% 400 \mathrm{mg}$ en orofaringe - seno piriforme - laringe - tráquea). Inducción propofol - atracurio. Mantenimiento: sevoflurane - atracurio remifentanilo. Extubación en quirófano, paciente vigil, sin bloqueo neuromuscular residual, normotermia y analgesia adecuada, sin complicaciones.

Comentarios: En el caso de una vía aérea difícil, el anestesiólogo cuenta con diferentes guías-protocolos (ASA DAS) y herramientas (laringoscopios - videolaringoscopios - mascara laríngea) para asegurar vía aérea y permitir una oxigenación adecuada de los tejidos. En este caso clínico se realizó intubación vigil mediante fibrobroncoscopia (Plan A) con el fin de mantener al paciente con tono muscular adecuado de vía aérea y ventilación espontanea, estabilidad hemodinámica y reducir el riesgo de pasaje de contenido purulento a tráquea. Desventajas que se pueden presentar: hemorragía - secreciones en vía aérea. Ante eventuales complicaciones se disponía de materiales para realizar cricotomía (Plan B) o traqueostomía quirúrgica (Plan C).

https://doi.org/10.25237/congresoclasa2019.95 